\title{
The Effect of Reducing Irradiation Temperature on the Structure and Radiation Embrittlement Mechanism of RPV Steels
}

\section{E. A. Kuleshova'1,2, B. A. Gurovich¹, A. S. Frolov¹, S. V. Fedotova ${ }^{1}$, D. A. Maltsev' E. V. Krikun ${ }^{1}$, D. A. Zhurko ${ }^{1}$, and Z. V. Bukina ${ }^{1}$}

${ }^{1}$ National Research Center «Kurchatov institute» Akademika Kurchatova sqr. 1, Moscow,123182, Russia

${ }^{2}$ National Research Nuclear University «MEPhl» (Moscow Engineering Physics Institute) Kashirskoe highway 31, Moscow,115409, Russia

\section{Abstract}

A complex research of RPV 15Kh2NMFA class 1 steel in different states was performed: in the initial state and after irradiatiion at different temperatures $\left(50-300^{\circ} \mathrm{C}\right)$. Low temperature $\left(50-140^{\circ} \mathrm{C}\right)$ irradiation was shown to cause the formation of dislocation

Corresponding Author:

E. V. Krikun

evkrikun@mail.ru

Received: 21 December 2017

Accepted: 15 April 2018

Published: 6 May 2018

Publishing services provided by Knowledge $\mathrm{E}$

(c) E. A. Kuleshova et al. This article is distributed under the terms of the Creative Commons

Attribution License, which permits unrestricted use and redistribution provided that the original author and source are credited.

Selection and Peer-review under the responsibility of the MIE-2017 Conference Committee. loops of ultrahigh density. At the same time radiation-induced precipitates, being the main radiation-induced hardening phase at irradiation temperature of VVER reactors $\left(\sim 300^{\circ} \mathrm{C}\right)$, were absent. This leads to a higher radiation embrittlement rate after low-temperature irradiation as compared with irradiation at operating temperatures of VVER-1000. The radiation embrittlement coefficient values are 8.7 and 1.45 for $(120-140)^{\circ} \mathrm{C}$ and $(290-315)^{\circ} \mathrm{C}$ irradiation temperature, respectively.

\section{Introduction}

Numerous studies demonstrated occurrence of two embrittlement mechanisms, which relative contribution can change during irradiation: hardening mechanism - (formation of radiation defects and radiation-induced precipitates) and non-hardening mechanism - (formation of grain boundary impurities segregation).

Irradiation temperature has a significant influence on the processes in steel that control each of the embrittlement mechanisms. On the one hand, the temperature decrease has to slowdown the point defect of crystal lattice and decrease the probability of vacancy - interstitial atom annihilation that will increase the radiation damage effectiveness, i.e. increase the rate of radiation defects accumulation. On the other hand, the slowdown of the point defect and atoms migration, i.e. the diffusion processes slowdown, can results in decreasing both the intensity of radiationinduced phase transformation and the rate of grain boundary segregation accumulation and, consequently, has to affect the radiation embrittlement rate of the steel 
at low-temperature irradiation as compared to similar steels that were irradiated at higher temperatures.

The most important characteristics for RPV-steels of nuclear VVER-type reactors are their resistance to thermal and radiation embrittlement. Radiation component of the ductile to brittle transition temperature (DBTT) shift can be represented as:

$$
\Delta T_{K}^{F}=A_{F} \cdot\left(\frac{F}{F_{0}}\right)^{m}
$$

where $\Delta T_{K}^{F}$ - radiation component of DBTT shift, $F$-fluence, $F_{0}$-normalization fluence, $A_{F}$ - radiation embrittlement coefficient, $\mathrm{m}$ - experimentally determined parameter.

The influence of irradiation on the steel structure degradation and the coefficient of radiation embrittlement $A_{F}$ within the temperature range $(50-315)^{\circ} \mathrm{C}$ was investigated.

\section{Materials and methods}

The paper focuses on VVER-1000 RPV 15Kh2NMFA class 1 base and weld metal specimens in the initial state and after accelerated irradiation in a research reactor up to fast neutron fluences ( $\mathrm{E}>0.5 \mathrm{MeV}$ ): at irradiation temperatures $(50-140)^{\circ} \mathrm{C}$ up to fluences $(4,5-8) 10^{22} \mathrm{~m}^{-2}$; at irradiation temperatures $(290-310)^{\circ} \mathrm{C}$ up to fluences $\sim 4,510^{23} \mathrm{~m}^{-2}$. Table 1 shows the chemical composition of 15Kh2NMFA class 1 steel.

TABLE 1: Chemical composition of 15Kh2NMFAA class 1 steel base metal (BM) and weld metal (WM).

\begin{tabular}{|c|c|c|c|c|c|c|c|c|c|c|}
\hline Material & \multicolumn{8}{|c|}{ Composition, wt. \% } \\
& C & Mn & Si & Ni & Cr & Mo & V & CU & P & S \\
\hline BM & 0.16 & 0.53 & 0.31 & 1.23 & 2.32 & 0.62 & 0.11 & 0.03 & $<0.005$ & $<0.003$ \\
WM & 0.08 & 0.98 & 0.24 & 1.18 & 1.92 & 0.59 & 0.017 & 0.04 & $<0.008$ & 0.006 \\
\hline
\end{tabular}

The mechanical tests (static tension and impact tests) were carried out to determine the yield strength change and DBTT temperature shift $\left(\Delta \mathrm{T}_{K}\right)$. Furthermore, to determine radiation-induced structural components - radiation-induced precipitates and radiation defects - analytical research methods were used: transmission electron microscopy (TEM) («Titan 80-300», FEl, USA); scanning electron microscopy (SEM) («Supra 40-VP», «Merlin», Zeiss, FRG) and atom-probe tomography (APT) («LEAP 4000 HR» (ameca, France). Grain boundary segregation was studied by Auger electron spectroscopy (AES) (PHI 700, Physical Electronics, Japan-USA). 


\section{Phase composition study of $15 \mathrm{Kh} 2 \mathrm{NMFA}$ class 1 steel and its weld in the initial state and after irradiation in (50-315) ${ }^{\circ} \mathrm{C}$ temperature range}

To reveal regularities of radiation hardening the structural studies were performed for materials in the initial state and after irradiation to a variety of fast neutron fluences in different temperature ranges.

\subsection{The study of initial hardening carbide and carbonitride phases}

Phase analysis of steel specimens in the initial state showed (according to micro diffraction patterns) that the base metal along with tempered bainite contains hardening phases: $\mathrm{Me}_{7} \mathrm{C}_{3},(\mathrm{Mo}, \mathrm{Cr})_{2} \mathrm{C}$ type carbides, $\mathrm{V}(\mathrm{C}, \mathrm{N})$ carbonitrides and non-metallic inclusions (manganese sulfides $\mathrm{MnS}$ and silicon oxides $\mathrm{SiO}_{2}$ ). The weld metal contains no carbonitrides. The number density of carbide phases also differs for the weld and base metal (see Table 2) due to the higher carbon content in the base metal.

TABLE 2: The number densities $N$ and average sizes $d$ of initial hardening phases in the initial state and after irradiation for base and weld metal specimens in $(50-315)^{\circ} \mathrm{C}$ temperature range.

\begin{tabular}{|c|c|c|c|c|c|c|c|}
\hline \multirow[t]{3}{*}{ Material } & \multirow[t]{3}{*}{ State } & \multicolumn{6}{|c|}{ Number density $(\rho)$ and average size $(d)$ of second phases } \\
\hline & & \multicolumn{2}{|c|}{$\mathrm{Me}_{7} \mathrm{C}_{3}$} & \multicolumn{2}{|c|}{$V(C, N)$} & \multicolumn{2}{|c|}{$\mathrm{Me}_{2} \mathrm{C}$} \\
\hline & & d, nm & $\mathrm{N}, 10^{19} \mathrm{~m}^{-3}$ & d, nm & $\mathrm{N}, 10^{22} \mathrm{~m}^{-3}$ & d, nm & $\mathrm{N}, 10^{20} \mathrm{~m}^{-3}$ \\
\hline BM & Initial & $40-50$ & $4.7 \pm 0.6$ & $6-10$ & $1.3 \pm 0.2$ & $15-25$ & $1.0 \pm 0.2$ \\
\hline BM & $\mathrm{F}_{1}=5.12 \cdot 10^{22} \mathrm{~m}^{-2}$ & $45-55$ & $5.2 \pm 0.7$ & $4-8$ & $1.4 \pm 0.3$ & $15-25$ & $0.8 \pm 0.2$ \\
\hline BM & $F_{2}=8.5 \cdot 10^{22} \mathrm{~m}^{-2}$ & $45-55$ & $5.5 \pm 0.7$ & $4-8$ & $1.1 \pm 0.3$ & $20-30$ & $1.2 \pm 0.2$ \\
\hline WM & Initial & $45-55$ & $1.9 \pm 0.2$ & - & - & $31 \pm 4$ & $4.0 \pm 1.1$ \\
\hline WM & $\mathrm{F}=4.0 \cdot 10^{21} \mathrm{~m}^{-2}$ & $50-60$ & $2.1 \pm 0.3$ & - & - & $25-35$ & $3.0 \pm 1.1$ \\
\hline
\end{tabular}

Thus, the irradiation did not cause a significant change of the initial hardening phases in the studied base and weld metal specimens: the number density and size of second phases match the corresponding values in the initial state (within the experimental data scatter). This means that the carbide and carbonitride phases do not additionally contribute to radiation hardening (the yield strength change) after irradiation in the specified temperature range. 


\subsection{The study of radiation-induced hardening phases and grain boundary segregation after irradiation in (50-140) ${ }^{\circ} \mathrm{C}$ temperature range}

In $50-140^{\circ} \mathrm{C}$ temperature range radiation-induced structural changes are mostly caused by formation of different types of dislocation loops with no precipitates formation. Figure 1 and Table 3 show the absence of radiation-induced hardening phases after low temperature irradiation in contrast to the irradiation in $(290-315)^{\circ} \mathrm{C}$ temperature range.

dark field TEM-images

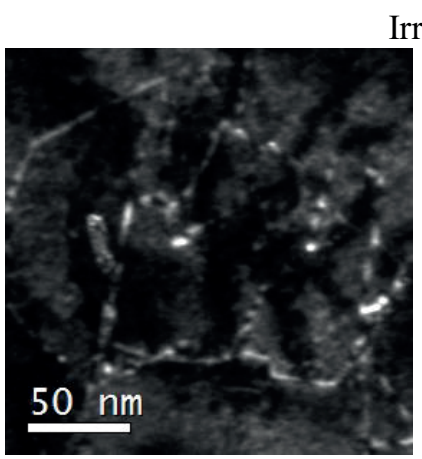

Dislocation loops

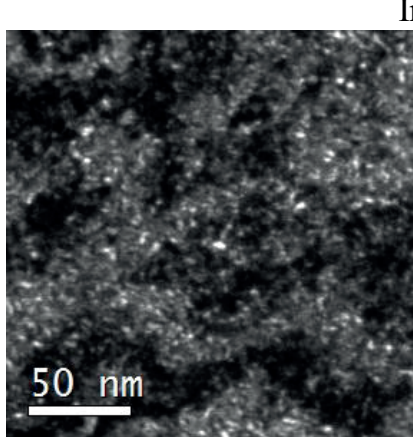

Dislocation loops
$3 \mathrm{~d}$ distribution maps of $\mathrm{Ni}$

(APT)

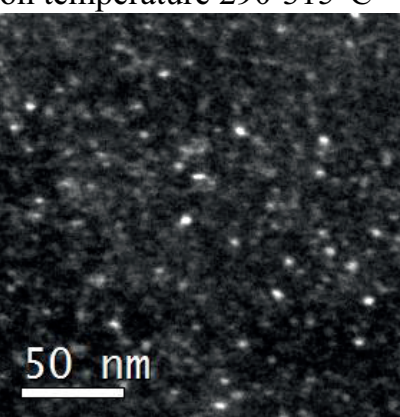

Precipitates

Irradiation temperature $50-140^{\circ} \mathrm{C}$
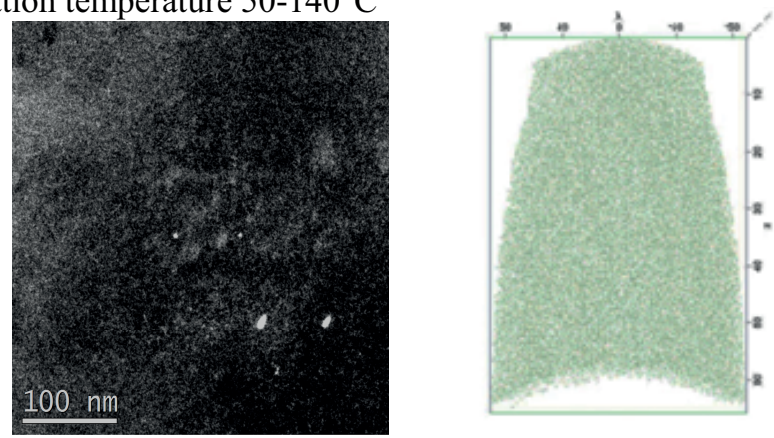

Precipitates

Figure 1: Radiation-induced structural elements at different irradiation temperature.

Table 3 and fig. 1 show that low-temperature irradiation (50-140) ${ }^{\circ} \mathrm{C}$ leads to significantly higher number density of dislocation loops as compared to the one for VVERtype temperature irradiation $\left(\sim 300^{\circ} \mathrm{C}\right)$. It can be seen that low-temperature irradiation up to $\sim 5$-8 times lower fast neutron fluence leads to formation of $\sim 250-500$ times higher density of dislocation loops with somewhat smaller sizes.

This leads to a greater rate of radiation hardening than for VVER-100o steel irradiated at $\sim 300^{\circ} \mathrm{C}$ : a close yield stress shift is achieved after irradiation at $\sim 300^{\circ} \mathrm{C}$ at a fluence 
TABLE 3: Number densities $\mathrm{N}$ and average sizes $<\mathrm{d}>$ of radiation-induced structural elements in 15Kh2NMFA class 1 steel after irradiation at different temperatures.
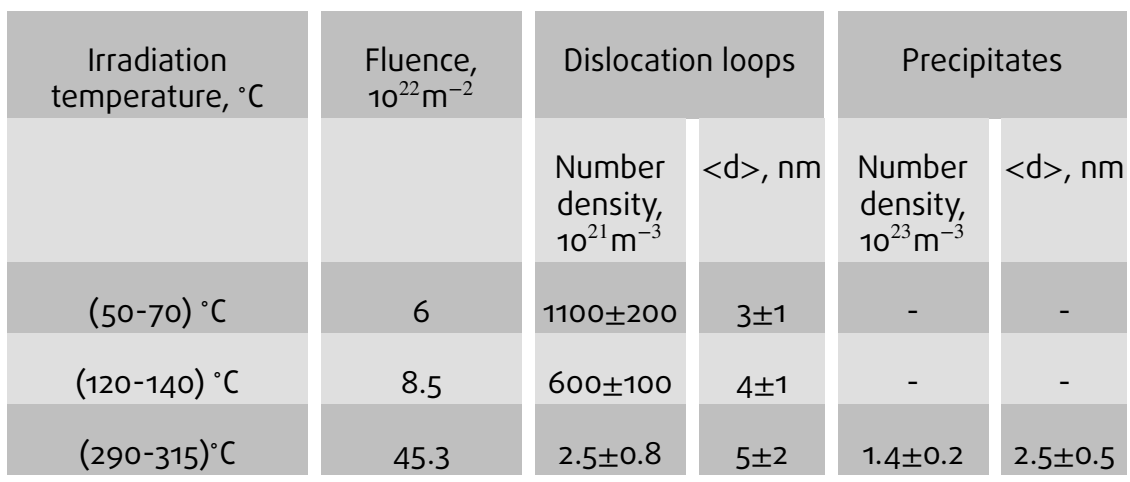

of an order of magnitude greater (see fig. 2). Thus, lowering the irradiation temperature led to a significant increase of radiation hardening.

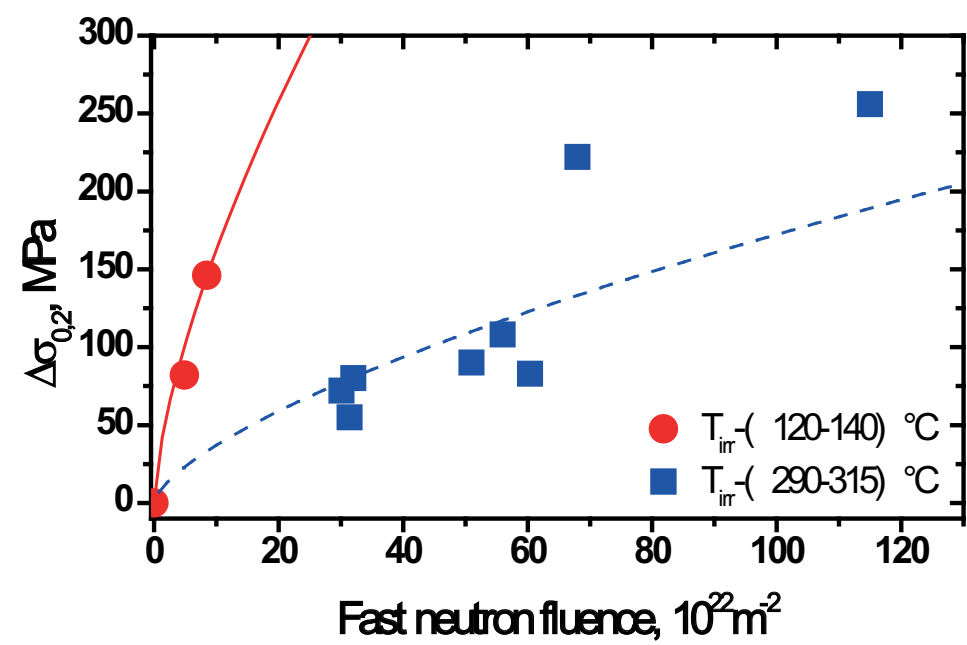

Figure 2: The dose dependence of yield strength for various irradiation temperatures.

The average loops size increases with the irradiation temperature increase. Thus, radiation hardening is solely due to dislocation loops accumulation. At this, its density is the higher, the lower is irradiation temperature.

TEM-studies of steels after irradiation at different temperatures revealed mainly the $<100>$ Burgers vector of dislocation loops for all the studied steels but dislocation with $<111>$ Burgers vector were also observed.

Dislocation loops in all the studied steels are mainly interstitial (its density is $\mathbf{1 . 5}$ times higher than for vacancy-type dislocation loops).

It was shown in [1] that the hardening due to $<100>$ and $1 / 2<111>$ types interstitials dislocation leads to a strong hardening in BCC metals. 
Vacancy loops are also known [2] to cause higher radiation hardening as compared to clusters. The higher is irradiation temperature, the lower is point defects contribution to radiation hardening.

That is why hardening is controlled by dislocation loops at low temperatures and their contribution is higher than at higher temperatures.

Fractographic studies demonstrated no brittle intergranular fracture in specimens irradiated at low temperature, indicating absence of grain boundary segregation. AES study neither revealed any grain boundary segregations as far as long-term liquid nitrogen cooling of the specimens has not resulted in getting a brittle intergranular fracture, and therefore gave no possibility to measure the grain boundary segregation. Thus, the results demonstrate that low-temperature irradiation causes no detectable grain boundary segregation due to low diffusion mobility of atoms (primarily phosphorus).

In sum, irradiation temperature effect on nanostructure evolution is the following.

\subsection{Low-temperature irradiation $\left(50-140^{\circ} \mathrm{C}\right)$}

In this temperature range radiation-induced structural changes are mostly formation of different types of dislocation loops with no precipitates formation. The average loops size increases with the irradiation temperature increase. Thus, radiation hardening is solely due to dislocation loops accumulation. At this, its density is the higher, the lower is irradiation temperature.

There is no segregation due to low diffusion mobility of atoms (primarily phosphorus). In this regard only hardening mechanism is responsible for the ductile-to-brittle transition temperature shift.

\subsection{VVER-type RPV irradiation temperature $\left(290-315^{\circ} \mathrm{C}\right)$}

In this temperature range radiation-induced structural changes are both formation of dislocation loops and precipitates. Besides, there is formation of grain boundary segregation. Radiation embrittlement is due to both hardening and non-hardening mechanisms.

Figure 3 shows the impact test results for determining DBTT shift for $15 \mathrm{Kh} 2 \mathrm{NMFA}$ class 1 steel specimens irradiated at different temperatures.

Thus, the observed structural changes under the influence of low-temperature irradiation lead to a significantly greater extent of radiation embrittlement compared with 


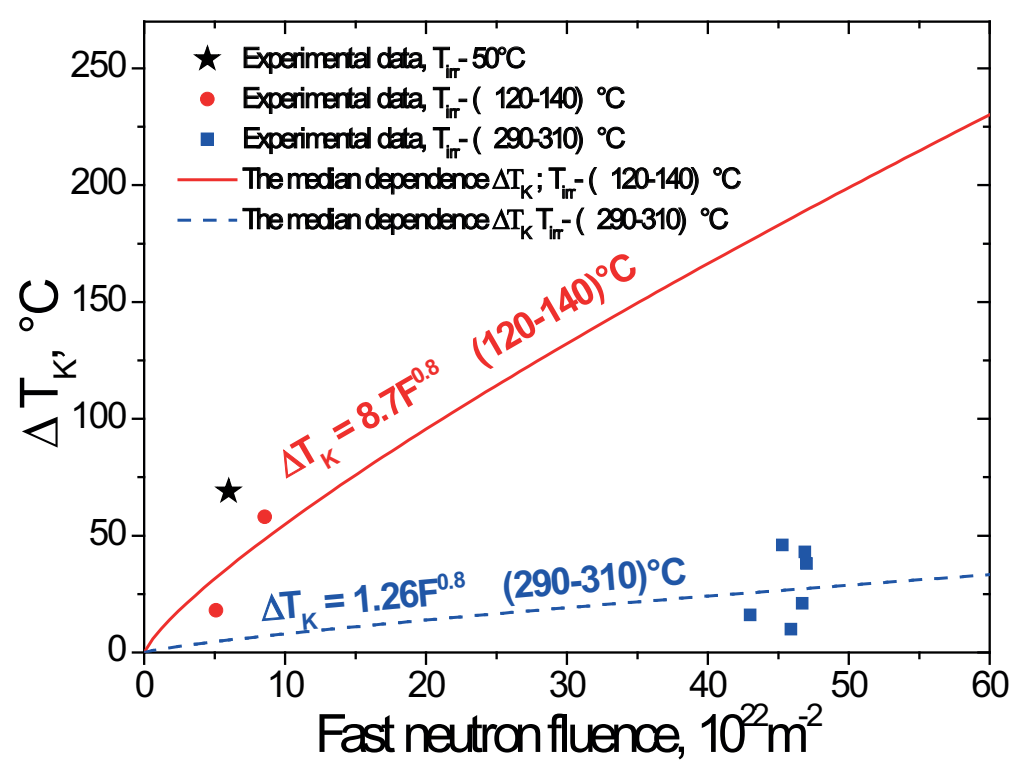

Figure 3: The dose dependence of the DBTT shift $\Delta T$ for $15 \mathrm{Kh} 2 \mathrm{NMFA}$ class 1 steel at different irradiation temperature.

irradiation at $\sim 300^{\circ} \mathrm{C}$, the operating temperature of VVER-1000 type RPV. Indeed, radiation embrittlement coefficient $A_{F}$ is 8.7 and 1.45 for irradiation at temperatures (120$140)^{\circ} \mathrm{C}$ and $(290-315)^{\circ} \mathrm{C}$, correspondingly, which significantly exceeds the normalized $\mathrm{A}_{F}$ values for these steels at the irradiation temperature $(290-315)^{\circ} \mathrm{C}[24]$

\section{Conclusions}

1. $15 \mathrm{Kh} 2 \mathrm{NMFAA}$ steel specimens were studied in initial state and after accelerated fast neutron ( $\mathrm{E}>0.5 \mathrm{MeV}$ ) irradiation in IR-8 up to fluences $\left(6 \cdot 10^{22} \mathrm{~m}^{-2} \div 4,5\right.$. $\left.10^{23} \mathrm{~m}^{-2}\right)$ in the temperature ranges $(50-140)^{\circ} \mathrm{C}$ and $(290-315)^{\circ} \mathrm{C}$.

2. Radiation hardening of $15 \mathrm{Kh} 2 \mathrm{NMFAA} \mathrm{RPV}$ steel at (290-315) ${ }^{\circ} \mathrm{C}$ temperature irradiation and fluences up to $\sim 4 \cdot 10^{23} \mathrm{~m}^{-2}$ is mainly due to radiation-induced precipitates formation of high density and some contribution of radiation defects, while radiation hardening at low-temperature irradiation $(50-140)^{\circ} \mathrm{C}$ is caused only by radiation defects formation - dislocation loops of ultrahigh density.

3. This leads to a higher radiation embrittlement rate at low-temperature irradiation: $\mathrm{A}_{F}$ values are 8.7 and 1.45 for irradiation temperature $(120-140)^{\circ} \mathrm{C}$ and (290$315)^{\circ} \mathrm{C}$, respectively. 


\section{References}

[1] D. Terentyev, D.J. Bacon, Yu.N. Osetsky 2010 Philosophical Magazine 90 (7-8) 10191033

[2] Stoller R.E. 1993 Proc. Int. Conf. "Effects of Radiation on materials".-Philadelphia: ASTM STP 1175. 301-307.

[3] Regulations to control the mechanical properties of the metal of operating VVER1000-type RPVs based on surveillance specimens test results 1.3.2.01.0061-2009. 